\title{
Adequacy of usual dietary intake and nutritional status among pregnant women in the context of nutrition transition: the DEPOSIT Study
}

\author{
Kathleen Abu-Saad ${ }^{1,2 *}$, Danit R. Shahar ${ }^{2}$, Drora Fraser $^{2}$, Hillel Vardi ${ }^{2}$, Michael Friger ${ }^{3}$, Arkardy Bolotin $^{3}$ \\ and Laurence S. Freedman ${ }^{4}$ \\ ${ }^{1}$ Cardiovascular Epidemiology Unit, Gertner Institute for Epidemiology and Health Policy Research, Sheba Medical Center, \\ Ramat Gan 52621, Israel \\ ${ }^{2}$ Department of Epidemiology and Health Services Evaluation, Faculty of Health Sciences, S. Daniel Abraham International \\ Center for Health and Nutrition, Ben-Gurion University of the Negev, Beer-Sheva 84105, Israel \\ ${ }^{3}$ Department of Epidemiology and Health Services Evaluation, Faculty of Health Sciences, Ben-Gurion University of the \\ Negev, Beer-Sheva 84105, Israel \\ ${ }^{4}$ Biostatistics Unit, Gertner Institute for Epidemiology and Health Policy Research, Sheba Medical Center, Ramat Gan 52621, \\ Israel
}

(Submitted 15 September 2011 - Final revision received 21 November 2011 - Accepted 6 December 2011 - First published online 23 January 2012)

\begin{abstract}
Bedouin Arabs in southern Israel are a traditionally semi-nomadic population undergoing the nutrition transition in a context of urbanisation. The effect of these changes on the nutritional status of pregnant women is unknown. The Dietary Exposures and Pregnancy Outcomes in a Society In Transition (DEPOSIT) study evaluated the adequacy of pregnant Bedouin women's usual dietary intake and their nutritional status. Dietary intake was assessed in a cross-sectional study design using repeat $24 \mathrm{~h}$ recall (24HR) questionnaires. The National Cancer Institute method was used to estimate the usual intake of selected nutrients. The Estimated Average Requirement (EAR) was used to evaluate nutrient intake adequacy. Measured weight and height data were used to calculate the participants' BMI. A total of $110924 \mathrm{HR}$ were obtained from 683 participants, of which $8 \%$ contained no animal-source protein and an additional $43 \%$ contained no haeme-Fe. Animal-source protein intake reached less than half of the EAR for most participants (71\%). Over $90 \%$ had inadequate intakes of Ca, $\mathrm{Fe}$, animal-source $\mathrm{Zn}$, vitamin A and folate. The probability of consuming haeme-source Fe was higher among urban than rural participants (OR 1·68, 95\% CI 1·17, 2·41), and among those with employed $v$. unemployed husbands (OR 1·81, 95\% CI 1·27, 2.58). Only 14\% reported consuming home-produced animal products. According to pre-pregnancy BMI, $42 \%$ were overweight or obese. The DEPOSIT study findings suggest that Bedouin Arab women are in need of interventions that address the co-existing problems of inadequate nutrient intakes and increased risk of obesity.
\end{abstract}

Key words: Maternal nutritional status: Pregnancy: Nutrition transition: Bedouin Arabs: Israel

The nutrition transition describes major shifts in human diet, nutritional status and nutrition-related disease ${ }^{(1)}$. These shifts occur at a differential pace in different populations. Most high-income countries are experiencing both the 'degenerative disease' stage, characterised by overnutrition and the development of chronic diseases; and the 'behavioural change' stage, characterised by reduced obesity rates and healthier ageing. Most low-income countries are experiencing both the 'receding famine' stage, in which undernutrition decreases but persists in the maternal and child population groups, and the beginnings of the 'degenerative disease' stage $^{(1)}$.
During pregnancy, women have increased nutrient requirements and an increased risk of undernutrition ${ }^{(2)}$. However, studies exploring the effects of the nutrition transition on pregnant women are limited. Simultaneous under- and overnutrition have been found among women in developing/ low-income societies ${ }^{(3-5)}$. While this has been determined primarily by anthropometric measurements, the evaluation of nutrient intake is also important, since during pregnancy adequate micronutrient intake and overall diet quality are essential for optimising the intra-uterine environment and preventing adverse outcomes ${ }^{(2,6-8)}$. Studies that accurately evaluate nutritional status and the adequacy of nutrient intakes

Abbreviations: 24HR, $24 \mathrm{~h}$ recall; DEPOSIT, Dietary Exposures and Pregnancy Outcomes in a Society In Transition; EAR, Estimated Average Requirement; NCI, National Cancer Institute; PNC, prenatal care; SES, socio-economic status; UI, usual intake; USDA, United States Department of Agriculture. 
among pregnant women are essential for the formulation of public health policy to improve maternal nutritional status during this critical life stage.

The Dietary Exposures and Pregnancy Outcomes in a Society In Transition (DEPOSIT) cohort study was designed to assess dietary intake and its association with birth outcomes among pregnant Bedouin Arab women in southern Israel. This traditionally semi-nomadic population is undergoing the nutrition transition in a context of sedentarisation and urbanisation $^{(9)}$. The effect of these changes on pregnant Bedouin women is unknown. The present article presents a crosssectional report of the DEPOSIT participants' nutritional status and dietary intake during pregnancy.

\section{Experimental methods}

\section{Subjects}

The Bedouin Arabs in southern Israel based their livelihood on animal husbandry and agriculture before their sedentarisation and urbanisation over the past 60 years ${ }^{(9,10)}$. At the time of the study, approximately half of the population lived in government-planned, urban-style towns. The other half lived in traditional villages and rural settings not connected to central infrastructures for the provision of many services (e.g. electricity, water, paved roads) ${ }^{(11,12)}$. The socio-economic status (SES) of the Bedouin, as measured by education, income and dependency-ratio levels, was the lowest of any population group in Israel $^{(13)}$.

\section{Sample}

The DEPOSIT sample was recruited from among parous Bedouin women with singleton pregnancies attending Ministry of Health prenatal care (PNC) clinics, or the outpatient PNC clinic of the regional hospital, Soroka University Medical Center. Both services were provided for a relatively low co-payment (US\$20-50 every 6 months) and were utilised by over $85 \%$ of pregnant Bedouin women at the time of the study ${ }^{(14)}$. All participants provided informed consent, and the study was approved by the Institutional Review Board (Helsinki Committee) of Soroka University Medical Center. The participants were interviewed at their PNC clinics.

\section{Dietary assessment}

We used repeat administrations (two) of a translated and modified United States Department of Agriculture (USDA) 24 hour recall (24HR) questionnaire to assess women's daily dietary intake during pregnancy ${ }^{(15,16)}$. The first $24 \mathrm{HR}$ was administered on the date of recruitment, and the second $24 \mathrm{HR}$ was conducted during each participant's subsequent PNC appointment, approximately 1 month later. The $24 \mathrm{HR}$ method asks respondents to recall and report all foods and beverages consumed in the previous $24 \mathrm{~h}$, using a standardised list of probes to improve the completeness of the recall ${ }^{(17)}$. The modification of the $24 \mathrm{HR}$ for this population has previously been described $^{(10,16)}$. Interviewers underwent extensive training in preparation for administering the $24 \mathrm{HR}$ in the local Arabic dialect, using locally adapted probes and a modified USDA food book and food models/portion-size booklet that included common Israeli and Bedouin foods, utensils and portion sizes. The interviewers also determined whether traditionally produced animal products (e.g. eggs, milk, yoghurt, cheese) were home-grown or store-bought. The dietary interviews were conducted over a 3-year period (2003-6) and were evenly distributed across the seasons.

\section{Food database}

Nutrient values were obtained from the database of the S. Daniel Abraham Center for Health and Nutrition, which is based on USDA Release SR19, and also includes common Israeli and Bedouin foods ${ }^{(16,18,19)}$. Previous studies ${ }^{(9,10,16)}$ in this population indicate that bread, which contains incomplete protein, is a major contributor to protein intake. Since lysine is the limiting amino acid in protein from wheat, we used the lysine values in the USDA database to calculate the lysine:protein ratio ( $\mathrm{mg}$ lysine/g protein) as an indicator of protein quality ${ }^{(20)}$. Refined grain products (e.g. white flour, bread, rice, pasta, cakes/cookies) are not fortified/enriched with micronutrients in Israel, and so unfortified USDA ingredients were used in all recipes. The nutrient composition of recipes was calculated using a computer program based on the concept of the American Food Information Analysis System program ${ }^{(21)}$. Trained nutritional data entry coders used this system to enter data into a database. Quality control conducted by the study coordinator and a registered dietitian involved: (1) checking each questionnaire for missing data within 1-3d of administration; (2) reviewing the data entry of each questionnaire for accuracy; (3) making cross-interview checks to detect unusual nutrient/portion size values.

\section{Demographic, anthropometric, obstetric and socio- economic status covariates}

Due to rural/urban differences in living conditions affecting the availability of perishable foods, we included residential status as a covariate in the statistical modelling of usual dietary intake (see the following text). Participants classified as urban lived in government-planned towns with access to service-provision infrastructures (e.g. mains electricity to power refrigerators); and those classified as rural lived in traditional villages/communities without such access. Participants' weight and height were measured at their PNC clinics using standardised equipment and procedures. Most participants did not have scales at home, and could not provide self-reported pre-pregnancy weight. Thus, pregnancy weight gained before PNC registration was estimated using Institute of Medicine (IOM) weight gain recommendations for a normal-weight woman per week and trimester of pregnancy $(0 \cdot 15 \mathrm{~kg} /$ week in trimester 1 and $0.42 \mathrm{~kg} /$ week in trimesters $2-3)^{(22)}$, and subtracted from the participants' measured weight at PNC initiation. Trimester of pregnancy at the time of the $24 \mathrm{HR}$ interview was calculated and interviews at $<14,14-27$ and $\geq 28$ weeks were coded as trimesters 1, 2 and 3, respectively. Husband's employment status 
(unemployed, employed) at the time of participant recruitment to the study was used as an indicator of SES.

\section{Statistical analysis}

The raw nutrient intake data of one $24 \mathrm{HR}$ were used to calculate mean nutrient intakes from food. Usual nutrient intakes were estimated from repeat $24 \mathrm{HR}$ questionnaires using the National Cancer Institute (NCI) method ${ }^{(23,24)}$, which has the capacity to provide robust intake estimates of episodically consumed foods/nutrients. Use of this method was important because of the potential for episodic consumption of perishable foods among the Bedouin. The method is based upon a statistical model that represents usual intake as the product of the probability to consume a food/nutrient on a given day, and the usual consumption-day amount. Statistical models constructed for the probability to consume and the amount consumed describe the within-person and betweenperson variation, as well as any associations with covariates. These models were run using mixtran_macro_v1.1.sas and distrib_macro_v1.1.sas available on the NCI website ${ }^{(24)}$. The mixtran macro fits a non-linear effects model to repeat $24 \mathrm{HR}$ using PROC NLMIXED. The distrib macro utilises a Monte Carlo method to estimate the distribution of usual intake from the parameter estimates produced by the mixtran macro. Usual intake estimates were obtained by using these programs on the DEPOSIT sample as a whole, and stratified by residential and SES status. The models took trimester at dietary interview (1st, 2nd, 3rd) into account, and were adjusted for repeat (1st or 2nd interview) and weekend (defined as Friday-Saturday) effects. Balanced repeated replication calculations ( $n$ 200) were used to obtain standard errors for the means of the usual intake distributions. The analysis was conducted using SAS 9.2. A level of $P<0.05$ was used to indicate statistical significance.

\section{Results}

A total of 701 parous, pregnant women were recruited to the study. The refusal rate was low ( $n 8,1 \cdot 1 \%)$, and due primarily to concerns about insufficient time for the interview before the PNC appointment. Of the 694 women enrolled, one woman withdrew from follow-up, and ten were excluded according to protocol for the birth outcomes study: eight due to nonsingleton pregnancies, one due to miscarriage and one due to a non-nutrition-related major congenital anomaly in the index birth that affects fetal growth (Trisomy 18). The present analysis includes all remaining participants ( $n$ 683, 97.3\% of the women enrolled).

Table 1 presents selected characteristics of the study sample by residential status. The participants' mean age was 28 years. The proportion of underweight women was low, while $42 \%$ were overweight or obese. Parity and unemployment rates were higher among rural than among urban participants, while educational levels were lower.

A single $24 \mathrm{HR}$ was obtained for all participants, and a second $24 \mathrm{HR}$ was obtained for 426 (62\%) of the participants. The proportion of participants with two $24 \mathrm{HR}$ was higher among rural than urban women (66 v. 58\%, $P=0.019$ ), but did not differ significantly by any other demographic or SES characteristic. Most $24 \mathrm{HR}$ were conducted during the 2nd trimester of pregnancy ( $71 \%$ ), while 7 and $22 \%$ were conducted during the 1st and 3rd trimesters, respectively. Of the 1109 24HR, $8 \%$ contained no protein from animal sources. Of those reporting animal-source foods, $43 \%$ contained no $\mathrm{Fe}$ from haeme (meat) sources (Fig. 1).

Only $14 \%$ of women reported consuming any homeproduced animal products, and the proportion was significantly higher among rural than urban women (Table 1). Most participants (78\%) reported taking a standard $\mathrm{Fe}$ (100 mg)/folic acid ( $400 \mu \mathrm{g}$ ) supplement, which they generally initiated after registering for PNC (at a gestational age of approximately 19 weeks). Only $2 \cdot 2 \%$ reported taking any type of supplement periconceptionally.

Table 2 contains the means with their standard errors, medians and interquartile ranges and percentage below recommended levels for the intake of selected nutrients from univariate analysis on the first $24 \mathrm{HR}$, and multivariate models using repeat $24 \mathrm{HR}$ and the NCI method to estimate usual intake (NCI-UI). The mean intake of participants with one $24 \mathrm{HR}$ did not differ significantly from those with two $24 \mathrm{HR}$ on energy $(P=0.794)$ or any of the other nutrients examined (data not shown). The NCI-UI mean for total protein met the Estimated Average Requirement (EAR), though less than half was from animal sources, and $76 \%$ of the women were below the recommended amino acid requirement for lysine $(51 \mathrm{mg} / \mathrm{g}$ protein). Mean NCI-UI estimates met or exceeded the EAR for carbohydrates, $\mathrm{Mg}$ and vitamin $\mathrm{C}$, but fell below the EAR/Adequate Intake for $\mathrm{Ca}$, both total and animalsource Fe and Zn, vitamin A and folate. Nutrient intakes did not differ by trimester of the $24 \mathrm{HR}$.

Bread and whole grains accounted for $>33 \%$ of the total protein intake (Fig. 2) and $>40 \%$ of the daily $\mathrm{Fe}$ and $\mathrm{Zn}$ intakes from food (Figs. 3 and 4). Only $10 \%$ of the Fe and $30 \%$ of the $\mathrm{Zn}$ intake came from haeme and animal-food sources, respectively.

Rural participants had significantly higher fibre and $\mathrm{Mg}$ intakes, but lower animal-source protein and haeme-Fe intakes than urban participants (Table 3). Haeme-Fe was the only nutrient to differ significantly by husband's employment status. In an NCI-UI model including both residential status and husband's employment status, the probability of consuming haeme-source Fe was higher among urban than rural participants (OR 1.68, 95\% CI 1·17, 2.41), and among those with employed $v$. unemployed husbands (OR 1.81, 95\% CI 1.27, 2.58; data not shown). Nevertheless, as the data in Table 3 indicate, the intake of animal-source nutrients was inadequate for most women, with 79 and $67 \%$ of rural and urban women, respectively, obtaining less than $50 \%$ of the protein EAR from animal-food sources, and over $90 \%$ in both groups having an inadequate intake of haeme-source Fe.

\section{Discussion}

The DEPOSIT findings suggest that this cohort of pregnant women is experiencing overlapping stages of the nutrition 
Table 1. Selected characteristics of the Dietary Exposures and Pregnancy Outcomes in a Society In Transition study population

(Mean values and standard deviations, medians and ranges, or percentages)

\begin{tabular}{|c|c|c|c|c|}
\hline Characteristics & Total $(n 683)$ & Rural (n 370) & Urban ( $n$ 313) & $P^{\star}$ \\
\hline \multicolumn{5}{|l|}{ Age (years) } \\
\hline Mean & $28 \cdot 4$ & $28 \cdot 6$ & $28 \cdot 0$ & \multirow[t]{2}{*}{0.168} \\
\hline SD & $5 \cdot 8$ & $5 \cdot 7$ & $5 \cdot 8$ & \\
\hline \multicolumn{5}{|l|}{ Parity } \\
\hline Median & 3 & 4 & 3 & \multirow[t]{2}{*}{0.006} \\
\hline Range & 13 & 13 & 11 & \\
\hline \multicolumn{5}{|l|}{ Pre-pregnancy weight $\dagger(\mathrm{kg})$} \\
\hline Mean & $62 \cdot 1$ & $61 \cdot 6$ & $62 \cdot 6$ & \multirow[t]{2}{*}{0.305} \\
\hline SD & $13 \cdot 3$ & $12 \cdot 8$ & $13 \cdot 9$ & \\
\hline \multicolumn{5}{|l|}{ Pre-pregnancy BMI† (\%) } \\
\hline Underweight $\left(<18.5 \mathrm{~kg} / \mathrm{m}^{2}\right)$ & $6 \cdot 4$ & $5 \cdot 7$ & $7 \cdot 3$ & \multirow[t]{4}{*}{0.153} \\
\hline Normal $\left(18.5-24.9 \mathrm{~kg} / \mathrm{m}^{2}\right)$ & $51 \cdot 2$ & $54 \cdot 7$ & $47 \cdot 2$ & \\
\hline Overweight $\left(25.0-29.9 \mathrm{~kg} / \mathrm{m}^{2}\right)$ & $26 \cdot 0$ & $22 \cdot 9$ & $29 \cdot 6$ & \\
\hline Obese $\left(\geq 30 \cdot 0 \mathrm{~kg} / \mathrm{m}^{2}\right)$ & $16 \cdot 4$ & $16 \cdot 7$ & $15 \cdot 9$ & \\
\hline \multicolumn{5}{|l|}{ Mother's educational level (\%) } \\
\hline None & $18 \cdot 6$ & $24 \cdot 7$ & $11 \cdot 3$ & \multirow[t]{4}{*}{$<0.001$} \\
\hline $1-9$ years & 48.4 & $53 \cdot 1$ & $42 \cdot 7$ & \\
\hline $10-12$ years & $29 \cdot 8$ & $20 \cdot 3$ & $41 \cdot 1$ & \\
\hline 13 years or more & $3 \cdot 2$ & 1.9 & 4.9 & \\
\hline \multicolumn{5}{|l|}{ Husband's educational level (\%) } \\
\hline None & 9.8 & $12 \cdot 9$ & $6 \cdot 1$ & \multirow[t]{4}{*}{0.001} \\
\hline $1-9$ years & $33 \cdot 3$ & $37 \cdot 2$ & $28 \cdot 7$ & \\
\hline $10-12$ years & 51.9 & $45 \cdot 8$ & $59 \cdot 0$ & \\
\hline 13 years or more & $5 \cdot 0$ & 4.0 & $6 \cdot 1$ & \\
\hline \multicolumn{5}{|l|}{ Mother's employment status (\%) } \\
\hline Unemployed & $94 \cdot 3$ & $97 \cdot 0$ & $91 \cdot 0$ & \multirow[t]{2}{*}{0.001} \\
\hline Employed & $5 \cdot 7$ & $3 \cdot 1$ & $9 \cdot 0$ & \\
\hline \multicolumn{5}{|l|}{ Husband's occupational status (\%) } \\
\hline Unemployed & 37.5 & $47 \cdot 4$ & $25 \cdot 4$ & \multirow[t]{2}{*}{$<0.001$} \\
\hline Employed & 62.5 & $52 \cdot 6$ & 74.6 & \\
\hline Current smokers (\%) & 1.8 & 1.6 & 1.9 & 0.763 \\
\hline Intake of home-produced animal protein (\%) & 13.5 & $16 \cdot 8$ & 9.6 & 0.006 \\
\hline
\end{tabular}

transition, in the wake of sedentarisation and urbanisation. Many participants had inadequate intakes of multiple nutrients, which is characteristic of the 'receding famine' stage ${ }^{(1)}$. At the same time, underweight appeared to be a minor problem, while overweight was relatively high, as is characteristic of the 'degenerative disease' stage.

At least $50 \%$ of the DEPOSIT cohort had inadequate intakes of complete protein, dietary fibre, $\mathrm{Zn}$ and vitamin $\mathrm{A}$, while over $95 \%$ had inadequate intakes of $\mathrm{Ca}, \mathrm{Fe}$ and folate. Since the statistical methods used reduced the risk of overestimating the prevalence of inadequate intake, these results are robust. They are based on $24 \mathrm{HR}$ data, which are widely relied upon for reporting the average daily nutrient intakes of groups because the means provide estimates that are not greatly affected by day-to-day within-person variation in dietary intake. However, 24HR data may underestimate energy and nutrient intakes, and may provide less reliable estimates of nutrients concentrated in episodically consumed foods ${ }^{(17)}$. We therefore used the NCI method, which provides more accurate estimates of episodically consumed foods/nutrients than other methods of estimating usual intake ${ }^{(23)}$. For the DEPOSIT cohort, in which animal-source protein and
haeme-Fe were episodically consumed, the NCI-UI estimates clearly reduced the influence of episodic zero-intake days as compared to the intake estimates from a single $24 \mathrm{HR}$, reducing the likelihood of underestimating intake. Furthermore, we used the EAR to evaluate the population-level adequacy of nutrient intakes rather than using the Recommended Daily Allowance, which may overestimate the population-level prevalence of inadequate intake ${ }^{(25)}$.

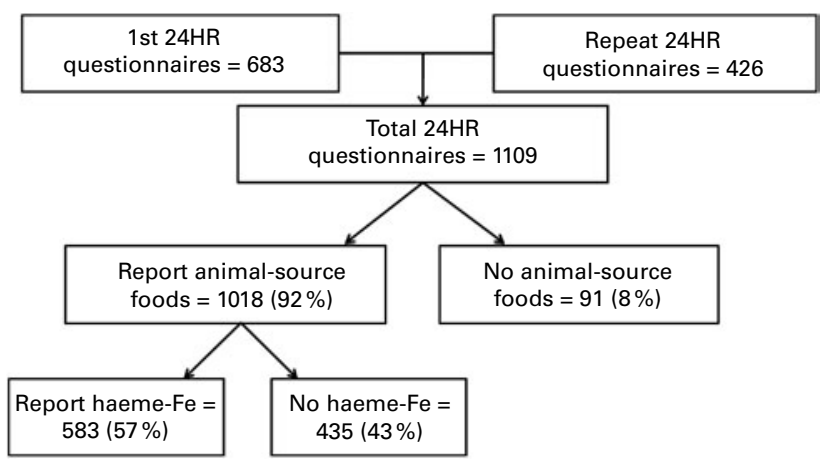

Fig. 1. Dietary intake data from $24 \mathrm{~h}$ recall $(24 \mathrm{HR})$ questionnaires showing number of non-consumption days of animal-source and haeme-iron foods. 
Table 2. Intake distribution of selected nutrients among the Dietary Exposures and Pregnancy Outcomes in a Society In Transition participants from univariate analysis on the first $24 \mathrm{~h}$ recall $(24 \mathrm{HR})$ and multivariate analysis using the National Cancer Institute method to estimate usual intake from repeat $24 \mathrm{HR}^{*}$

(Mean values with their standard errors, medians and quartiles, $n 683$ )

\begin{tabular}{|c|c|c|c|c|c|c|c|}
\hline \multirow[b]{2}{*}{ Nutrient } & \multirow[b]{2}{*}{ Mean } & \multirow[b]{2}{*}{ SE } & \multirow[b]{2}{*}{ Median } & \multicolumn{2}{|c|}{ Quartiles } & \multirow[b]{2}{*}{ EAR/Al } & \multirow[b]{2}{*}{ Below EAR (\%) } \\
\hline & & & & $1 \mathrm{st}$ & 3rd & & \\
\hline \multicolumn{8}{|l|}{ Energy (kJ) } \\
\hline $24 \mathrm{HR}$ & 7611 & 117 & 7150 & 5326 & 9314 & \multirow[t]{2}{*}{ NA† } & \\
\hline Estimated usual intake & 7518 & 105 & 7481 & 6243 & 8828 & & \\
\hline \multicolumn{8}{|l|}{ Total protein $(\mathrm{g})$} \\
\hline $24 \mathrm{HR}$ & $59 \cdot 1$ & $1 \cdot 1$ & $55 \cdot 2$ & $38 \cdot 9$ & $74 \cdot 6$ & \multirow[t]{2}{*}{$58 \ddagger$} & 53 \\
\hline Estimated usual intake & 58.9 & 0.9 & $57 \cdot 7$ & $46 \cdot 9$ & $69 \cdot 8$ & & 50 \\
\hline \multicolumn{8}{|l|}{ Animal-source protein (g) } \\
\hline $24 \mathrm{HR}$ & $22 \cdot 8$ & $0 \cdot 8$ & $18 \cdot 4$ & $7 \cdot 3$ & 33.1 & \multirow{2}{*}{$29.0 \S$} & 69 \\
\hline Estimated usual intake & 24.5 & $0 \cdot 8$ & $21 \cdot 5$ & $16 \cdot 4$ & $30 \cdot 9$ & & 71 \\
\hline \multicolumn{8}{|l|}{ Lysine score (mg/g protein)\| } \\
\hline $24 \mathrm{HR}$ & 47.5 & $0 \cdot 8$ & $47 \cdot 3$ & 39.5 & $55 \cdot 2$ & \multirow[t]{2}{*}{$51 \cdot 0 \|$} & 61 \\
\hline Estimated usual intake & $47 \cdot 6$ & 0.4 & $47 \cdot 6$ & 44.4 & $50 \cdot 8$ & & 76 \\
\hline \multicolumn{8}{|l|}{ Total fat $(\mathrm{g})$} \\
\hline $24 \mathrm{HR}$ & $56 \cdot 3$ & 1.2 & $50 \cdot 2$ & $32 \cdot 3$ & 73.0 & \multirow[t]{2}{*}{ NA† } & \\
\hline Estimated usual intake & $56 \cdot 5$ & $1 \cdot 1$ & $55 \cdot 0$ & $44 \cdot 6$ & $66 \cdot 8$ & & \\
\hline \multicolumn{8}{|l|}{ Carbohydrates (g) } \\
\hline $24 \mathrm{HR}$ & $281 \cdot 3$ & $4 \cdot 1$ & $265 \cdot 6$ & $205 \cdot 7$ & 339.1 & \multirow[t]{2}{*}{175} & 14 \\
\hline Estimated usual intake & $280 \cdot 9$ & 3.9 & $277 \cdot 3$ & $234 \cdot 3$ & 323.4 & & 4 \\
\hline \multicolumn{8}{|l|}{ Fibre $(\mathrm{g})$} \\
\hline $24 \mathrm{HR}$ & $27 \cdot 6$ & 0.6 & 24.5 & $15 \cdot 8$ & $36 \cdot 1$ & 28 & 58 \\
\hline Estimated usual intake & 27.5 & 0.6 & $26 \cdot 8$ & $21 \cdot 7$ & $32 \cdot 6$ & & 55 \\
\hline $\mathrm{Ca}(\mathrm{mg})$ & & & & & & & \\
\hline $24 \mathrm{HR}$ & $421 \cdot 6$ & $10 \cdot 2$ & 379.9 & 234.5 & 541.5 & 1000 & 97 \\
\hline Estimated usual intake & $422 \cdot 0$ & $9 \cdot 2$ & $405 \cdot 1$ & $316 \cdot 4$ & 509.8 & & 100 \\
\hline Total Fe (mg) & & & & & & & \\
\hline $24 \mathrm{HR}$ & $10 \cdot 81$ & 0.23 & 9.83 & 6.48 & $13 \cdot 67$ & 22 & 96 \\
\hline Estimated usual intake & $10 \cdot 80$ & 0.20 & $10 \cdot 54$ & $8 \cdot 67$ & $12 \cdot 65$ & & 100 \\
\hline Haeme-Fe (mg) & & & & & & & \\
\hline $24 \mathrm{HR}$ & $1 \cdot 11$ & 0.09 & 0.41 & 0.00 & 1.35 & 169 & 99 \\
\hline Estimated usual intake & 1.01 & 0.06 & 0.92 & 0.55 & 1.38 & & 100 \\
\hline $\mathrm{Mg}(\mathrm{mg})$ & & & & & & & \\
\hline $24 \mathrm{HR}$ & $310 \cdot 6$ & $6 \cdot 4$ & $275 \cdot 7$ & $182 \cdot 1$ & 399.5 & 290 & 52 \\
\hline Estimated usual intake & $311 \cdot 1$ & $6 \cdot 1$ & $302 \cdot 2$ & 245.9 & $367 \cdot 4$ & & 44 \\
\hline Total Zn (mg) & & & & & & & \\
\hline $24 \mathrm{HR}$ & 8.33 & $0 \cdot 17$ & $7 \cdot 60$ & $5 \cdot 17$ & $10 \cdot 63$ & 9.5 & 67 \\
\hline Estimated usual intake & 8.39 & $0 \cdot 16$ & $8 \cdot 17$ & $6 \cdot 67$ & 9.88 & & 70 \\
\hline Animal-source Zn (mg) & & & & & & & \\
\hline $24 \mathrm{HR}$ & 2.57 & $0 \cdot 10$ & 1.88 & 0.83 & 3.40 & $7 \cdot 13^{\star \star}$ & 94 \\
\hline Estimated usual intake & $2 \cdot 66$ & $0 \cdot 10$ & $2 \cdot 36$ & 1.65 & 3.34 & & 99 \\
\hline Vitamin C (mg) & & & & & & & \\
\hline $24 \mathrm{HR}$ & 81.9 & $2 \cdot 7$ & $62 \cdot 2$ & $34 \cdot 3$ & 104.6 & 70 & 56 \\
\hline Estimated usual intake & $82 \cdot 3$ & $2 \cdot 6$ & 78.9 & $61 \cdot 9$ & $98 \cdot 6$ & & 37 \\
\hline Vitamin A (RAE) & & & & & & & \\
\hline $24 \mathrm{HR}$ & 531.0 & $94 \cdot 1$ & 237.1 & 139.9 & 386.5 & 550 & 88 \\
\hline Estimated usual intake & $369 \cdot 8$ & $18 \cdot 9$ & $350 \cdot 4$ & 280.9 & $436 \cdot 0$ & & 92 \\
\hline Folate $(\mu \mathrm{g})$ & & & & & & & \\
\hline $24 \mathrm{HR}$ & $230 \cdot 1$ & $6 \cdot 0$ & $200 \cdot 9$ & 137.5 & $280 \cdot 6$ & 520 & 97 \\
\hline Estimated usual intake & $227 \cdot 4$ & $5 \cdot 1$ & $218 \cdot 1$ & $176 \cdot 7$ & $269 \cdot 8$ & & 100 \\
\hline
\end{tabular}

EAR, Estimated Average Requirement; AI, Adequate Intake; NA, not applicable; RAE, retinol activity equivalent.

${ }^{*}$ Adjusted for selected dietary interview characteristics repeat effect (1st or 2nd 24HR), and weekend effect (weekday or weekend).

† No EAR/Al set for these parameters.

† EAR for protein calculated as $0.88 \mathrm{~g} / \mathrm{kg}$ per $\mathrm{d} \times$ mean weight of participants at interview $(66.4 \mathrm{~kg})=58 \mathrm{~g} / \mathrm{d}$ protein .

$\S$ Half of protein EAR.

|| Lysine score (51 mg lysine/g protein) serves as an indicator of the protein quality in diets in which wheat is a major source of protein ${ }^{(20)}$

I Daily Fe intake recommendation (EAR $=22 \mathrm{mg})$ is based on the assumption that $75 \%(16 \mathrm{mg})$ is from haeme sources ${ }^{(31)}$.

${ }^{\star *}$ Daily $\mathrm{Zn}$ intake recommendation (EAR $\left.=9.5 \mathrm{mg}\right)$ is based on the assumption that $75 \%(7.13 \mathrm{mg})$ is from animal-food sources ${ }^{(31)}$.

Consideration of the food sources of key nutrients raised additional concerns about the adequacy of the DEPOSIT participants' intake. The mean daily protein intake reached the pregnancy EAR, and food groups containing complete proteins, such as poultry/eggs/fish (19\%), dairy products (12\%) and red/organ meat (7\%), were important contributors to protein intake. Nevertheless, over $50 \%$ came from cereal/plant foods, which contain incomplete proteins that may not be of an adequate quality to meet all indispensible amino acid requirements $^{(20)}$. Bread, which was the main contributor to 


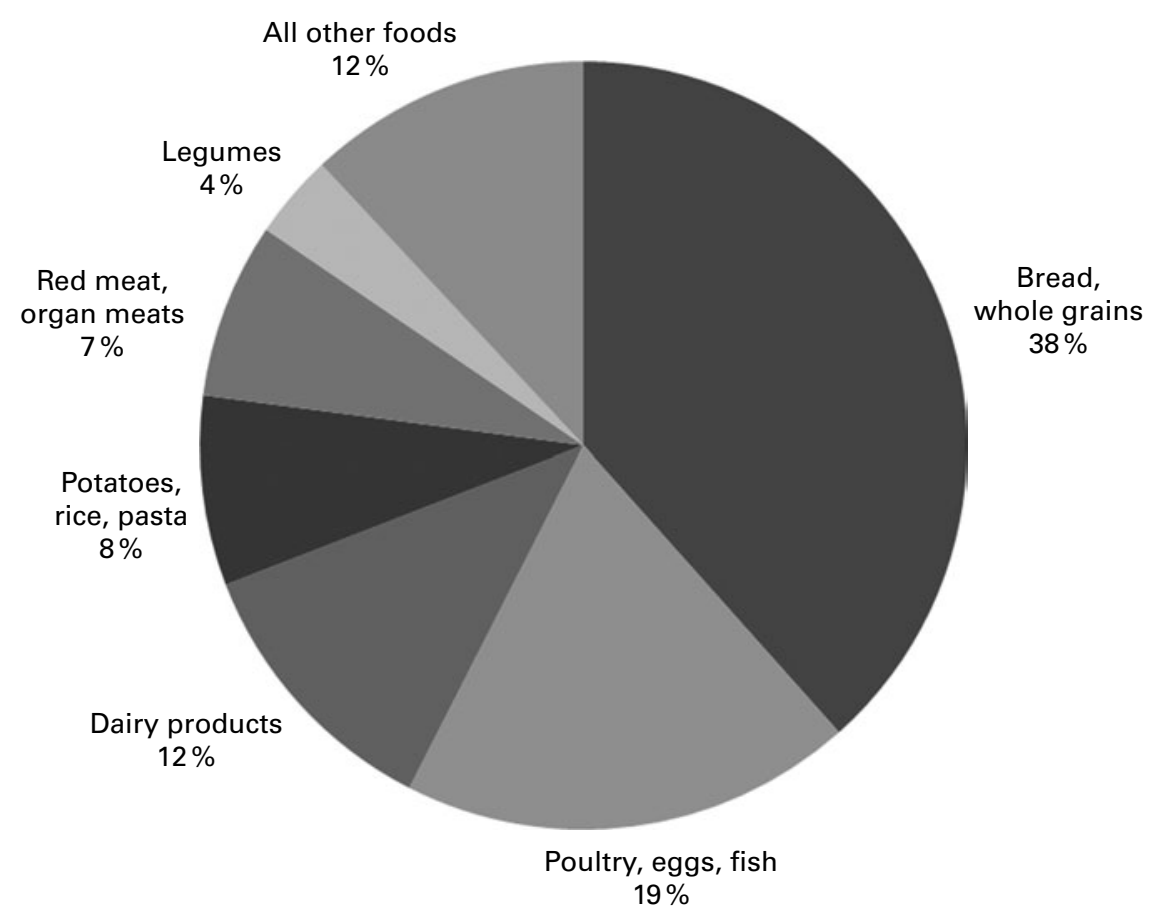

Fig. 2. Protein intake among Dietary Exposures and Pregnancy Outcomes in a Society In Transition participants: major food contributors.

protein intake $(38 \%)$, is consumed in high amounts in this population, partly due to the practice of using bread as a utensil for eating from common plates, and partly due to the low SES level ${ }^{(9)}$. Lysine is the limiting amino acid in wheatsource protein, which contains only $25 \mathrm{mg}$ lysine/g protein; while the lysine requirement in protein of adequate quality is $51 \mathrm{mg}$ lysine/g protein ${ }^{(20)}$. Although the intake of complementary foods that are rich in lysine, such as legumes, was traditionally high in the Bedouin population ${ }^{(10)}$, among the DEPOSIT participants, legumes provided only $4 \%$ of the total protein intake. Our findings indicate that this did not compensate for the low level of lysine in the wheat-based protein staples, as the overall protein intake of $76 \%$ of women did not meet the lysine requirement. The lysine EAR for pregnant

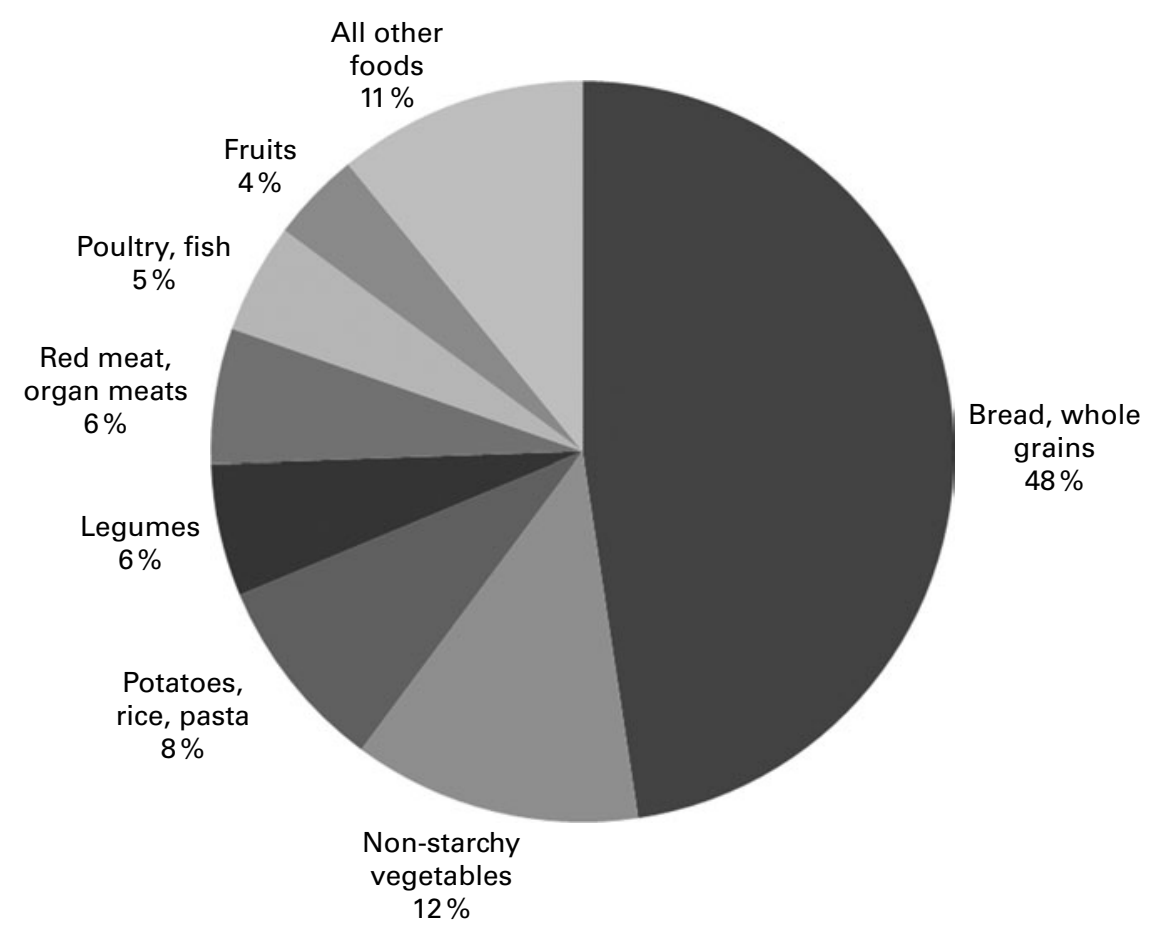

Fig. 3. Iron intake among Dietary Exposures and Pregnancy Outcomes in a Society In Transition participants: major food contributors. 


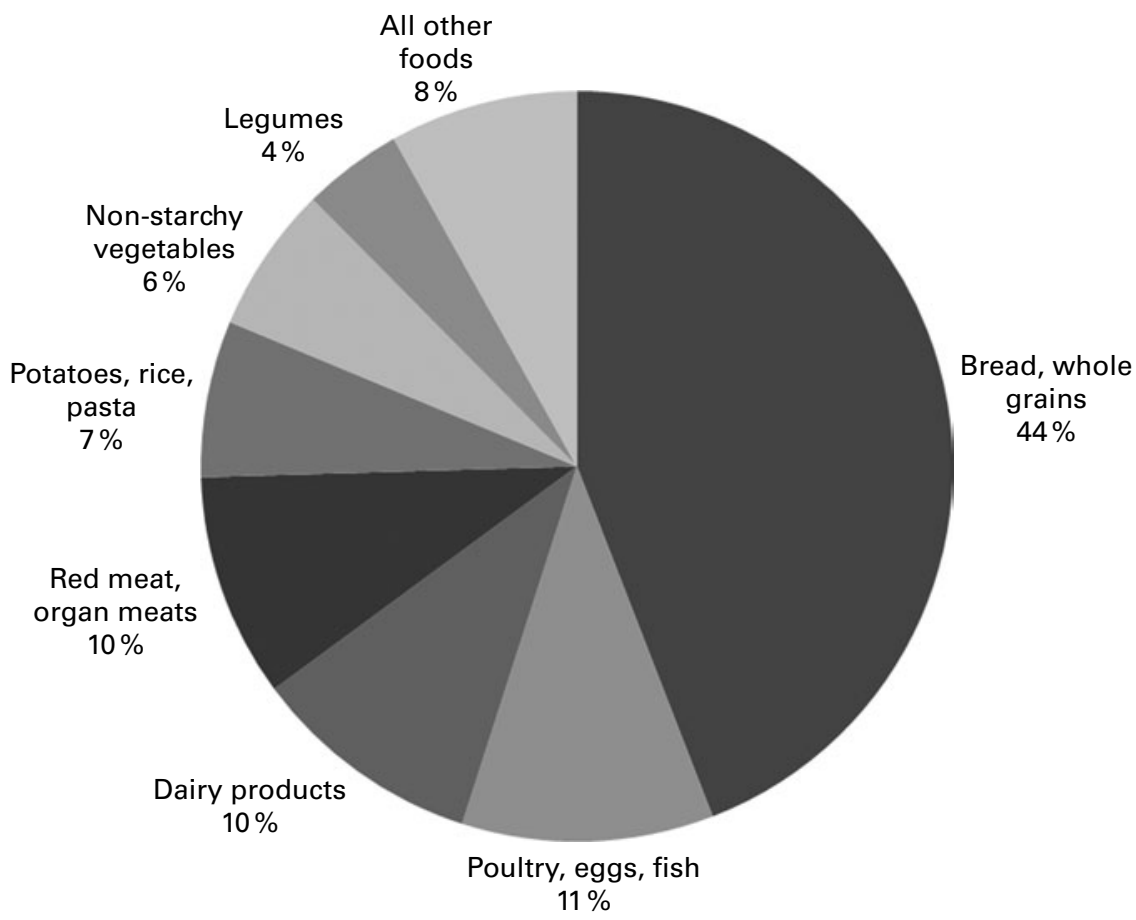

Fig. 4. Zinc intake among Dietary Exposures and Pregnancy Outcomes in a Society In Transition participants: major food contributors.

women $(41 \mathrm{mg} / \mathrm{kg}$ per $\mathrm{d})$ is higher than that for other adults $(31 \mathrm{mg} / \mathrm{kg}$ per $\mathrm{d})$ due to the rapid growth occurring during this life stage ${ }^{(20)}$. Animal and human studies have shown that inadequate lysine intake during rapid growth phases is detrimental to normal development ${ }^{(26,27)}$. Unfortunately, few contemporary studies of dietary intake during pregnancy distinguish between animal- and plant-source protein, or evaluate the intake of limiting amino acids, even in populations that rely heavily on cereals/wheat for their protein intake ${ }^{(28-30)}$. An examination of protein sources and their

Table 3. Multivariate analysis comparing estimated usual nutrient intakes among rural and urban Dietary Exposures and Pregnancy Outcomes in a Society In Transition participants, adjusted for selected dietary interview characteristics*

(Mean values with their standard errors)

\begin{tabular}{|c|c|c|c|c|c|c|c|c|}
\hline \multirow[b]{3}{*}{ Nutrient } & \multicolumn{5}{|c|}{ Estimated usual intake } & \multirow[b]{3}{*}{ EAR } & \multirow{2}{*}{\multicolumn{2}{|c|}{$\begin{array}{c}\text { Percentage } \\
\text { below the EAR }\end{array}$}} \\
\hline & \multicolumn{2}{|c|}{ Rural ( $n$ 370) } & \multicolumn{2}{|c|}{ Urban (n 313) } & \multirow[b]{2}{*}{$P$} & & & \\
\hline & Mean & SE & Mean & SE & & & Rural & Urban \\
\hline Energy (kJ) & 7535 & 138 & 7703 & 163 & $0.694 \dagger$ & NAł & & \\
\hline Total protein (g) & $58 \cdot 1$ & $1 \cdot 3$ & $60 \cdot 5$ & 1.5 & $0.303 \dagger$ & $58 \S$ & $53 \cdot 0$ & $47 \cdot 4$ \\
\hline Animal-source protein $(\mathrm{g})$ & $22 \cdot 4$ & $1 \cdot 1$ & $27 \cdot 0$ & 1.4 & $0.018 \dagger$ & $29 \|$ & $77 \cdot 1$ & $65 \cdot 0$ \\
\hline Lys score (mg/g protein) & $46 \cdot 4$ & 0.48 & $49 \cdot 0$ & 0.58 & $0.054 \dagger$ & 519 & 83.4 & $67 \cdot 1$ \\
\hline Fibre $(g)$ & $29 \cdot 0$ & 0.8 & $25 \cdot 7$ & 0.8 & $0.002 \dagger$ & 28 & $48 \cdot 7$ & 64.9 \\
\hline Total Fe (mg) & $10 \cdot 92$ & $0 \cdot 27$ & $10 \cdot 61$ & 0.30 & $0.341 \dagger$ & 22 & $99 \cdot 8$ & $99 \cdot 9$ \\
\hline Haeme-Fe (mg) & 0.90 & 0.07 & $1 \cdot 13$ & 0.09 & $0.004^{\star \star}$ & $16 \dagger \dagger$ & $100 \cdot 0$ & $100 \cdot 0$ \\
\hline Vitamin C (mg) & $82 \cdot 7$ & $3 \cdot 3$ & 81.4 & $3 \cdot 6$ & $0.913 \dagger$ & 70 & $36 \cdot 5$ & $38 \cdot 1$ \\
\hline Vitamin A (RAE) & $347 \cdot 9$ & $20 \cdot 7$ & $391 \cdot 7$ & $24 \cdot 2$ & $0.118 \dagger$ & 550 & $94 \cdot 2$ & $88 \cdot 7$ \\
\hline $\mathrm{Mg}(\mathrm{mg})$ & $328 \cdot 8$ & 6.4 & $288 \cdot 9$ & $8 \cdot 6$ & $0.006 \dagger$ & 290 & $36 \cdot 8$ & $54 \cdot 6$ \\
\hline Total Zn (mg) & $8 \cdot 60$ & $0 \cdot 20$ & 8.09 & 0.23 & $0.070 \dagger$ & 9.5 & $66 \cdot 7$ & $74 \cdot 2$ \\
\hline Animal-source Zn (mg) & $2 \cdot 48$ & 0.12 & $2 \cdot 87$ & 0.14 & $0.071^{\star *}$ & $7 \cdot 1 \ddagger \ddagger$ & 93.4 & 89.5 \\
\hline
\end{tabular}

EAR, Estimated Average Requirement; NA, not applicable; RAE, retinol activity equivalent.

${ }^{*}$ Adjusted for repeat effect (1st or 2 nd $24 \mathrm{~h}$ recall), and weekend effect (weekday or weekend).

$\dagger P$ value from the amount model of the National Cancer Institute method for estimating usual intake.

$\ddagger$ No EAR set for energy.

$\S$ EAR for protein calculated as $0.88 \mathrm{~g} / \mathrm{kg}$ per $\mathrm{d} \times$ mean weight of participants at interview $(66.4 \mathrm{~kg})=58 \mathrm{~g} / \mathrm{d}$ protein.

\| Half of protein EAR.

ๆ Lysine score (51 mg lysine/g protein) serves as an indicator of the protein quality in diets in which wheat is a major source of protein ${ }^{(20)}$.

${ }^{\star \star} P$ value for probability model of the National Cancer Institute method for estimating usual intake of episodically consumed foods.

t†Daily $\mathrm{Fe}$ intake recommendation $(\mathrm{EAR}=22 \mathrm{mg})$ is based on the assumption that $75 \%(16 \mathrm{mg})$ is from haeme sources ${ }^{(31)}$.

㧊Daily $\mathrm{Zn}$ intake recommendation (EAR $=9.5 \mathrm{mg}$ ) is based on the assumption that $75 \%(7.1 \mathrm{mg})$ is from animal-food sources ${ }^{(31)}$. 
limiting amino acids in the present study indicated that the intake of complete protein was suboptimal for the requirements of pregnancy.

High proportions of the participants' $\mathrm{Fe}$ and $\mathrm{Zn}$ intakes (90 and $70 \%$, respectively) came from bread and other plant sources. The EAR for Fe and $\mathrm{Zn}$ are based upon the assumption that the majority comes from haeme source/animalsource foods ${ }^{(31)}$. The bioavailability of dietary $\mathrm{Fe}$ and $\mathrm{Zn}$ from wheat-based foods is inhibited by their phytate-content ${ }^{(32)}$. Although $78 \%$ of women reported taking Fe supplements, most initiated supplementation approximately midway through the pregnancy. There is evidence that maternal Fe deficiency anaemia before and in early pregnancy, and late initiation of Fe supplementation, increase the risk of preterm and low birth weight delivery ${ }^{(33)}$.

The DEPOSIT participants' nutrient intake was associated with living conditions and SES. The amount of animalsource protein and the probability of haeme-source $\mathrm{Fe}$ intake were significantly lower for rural than for urban women, probably due to rural living conditions that made perishable foods harder to access and preserve. The probability of haeme-Fe intake was also significantly lower among women with unemployed as compared to women with employed husbands. Poorer nutrient intake among rural $v$. urban and low $v$. high SES pregnant women is a common finding ${ }^{(28)}$, though in some cases these disparities have been alleviated by food production in rural communities ${ }^{(34)}$. While traditionally the Bedouin produced milk and other animal products $^{(10)}$, a very low proportion of the DEPOSIT participants reported consuming home-grown animal-source foods. Reports from the Bedouin population undergoing sedentarisation and urbanisation in Jordan showed deficiencies of the micronutrients found primarily in animal products (e.g. Fe, $\mathrm{Zn}$, vitamin $\mathrm{A}, \mathrm{Ca}$ ) among pre-school children ${ }^{(35)}$. The authors suggested that the Bedouin's nutritional situation declined with the loss of home-produced animal products, given the persistence of poverty after sedentarisation and urbanisation. Similarly, the DEPOSIT participants' intake of animal-source/ complete protein, $\mathrm{Zn}$ and haeme-Fe suggests that existing urbanisation amenities and employment levels fail to ensure adequate nutrient intakes for the majority ( $\geq 65 \%$ ) of pregnant women.

Despite high rates of inadequate nutrient intake, overweight/obesity emerged as a growing problem, as has been found in other low- and high-income populations ${ }^{(2-5,36-38)}$. Maternal obesity during pregnancy is associated with numerous adverse outcomes, including pregnancy-induced hypertension, gestational diabetes, thromboembolism, congenital anomalies, spontaneous intra-uterine death, macrosomia and caesarean section delivery ${ }^{(38)}$. Children born to obese mothers are also at higher risk of obesity in adolescence and adulthood $^{(38)}$. Since there is some evidence of a positive association between parity and obesity ${ }^{(39)}$, the reproductive years may be a key period during which to intervene to reduce this phenomenon and its consequent increased risk for other chronic diseases.

\section{Limitations}

The present study has a number of limitations. The DEPOSIT sample did not include nulliparous women, among whom the prevalence of underweight and overweight may differ, especially if its development is linked to parity. Women not attending PNC clinics were also not represented in the sample. Available data indicate that approximately 15-20\% of Negev Bedouin women do not attend PNC clinics, due primarily to access, transportation and cost barriers ${ }^{(14,40)}$. These women may represent a subgroup with a lower SES and diet quality level than that found in the DEPOSIT cohort. We did not have a repeat $24 \mathrm{HR}$ for all participants. While it is ideal to have multiple $24 \mathrm{HR}$ repeats for each respondent, this is not always possible in practice. An advantage of the NCI method for estimating usual intake is that it can deal with a situation in which only one $24 \mathrm{HR}$ is available for a proportion of the participants, as long as there are enough participants with two or more repeats ${ }^{(41)}$. In our case, $62 \%$ of the participants had a repeat $24 \mathrm{HR}$ ( $n$ 426), which is sufficient to reliably estimate usual intake distributions. Although there was a slight over-representation of rural women among those with two $24 \mathrm{HR}$ repeats, the within-person variance among rural and urban women was very similar, and therefore we would not expect this to bias the estimation of the usual distribution. We did not find further differences between respondents with one or two $24 \mathrm{HR}$ repeats in any of the variables we examined. Data from $24 \mathrm{HR}$ may underestimate intake. The literature reports energy intake underestimates from $24 \mathrm{HR}$ data ranging from 3 to $26 \%{ }^{(17)}$, and we reported an energy intake underestimation of $11-14 \%$ in $24 \mathrm{HR}$ data collected from Bedouin women ${ }^{(16)}$. Even allowing for an underestimation of this magnitude, the finding that a substantial proportion of the DEPOSIT cohort was at risk of inadequate intake of multiple nutrients persists. Measured pre-pregnancy weight was not available, but was estimated from measured weight at the first PNC visit. Our overweight/obesity prevalence estimate may be low, since we calculated pregnancy weight gain using the recommended weight gain/week for normal-weight women, which is higher than that for overweight/obese women ${ }^{(22)}$. Given the substantial prevalence of overweight/obesity we observed, obtaining measured pre-pregnancy weight data in this population should be a public health priority.

While taking the study limitations into account, repeat $24 \mathrm{HR}$ and a robust method for estimating usual intake indicate that the diet of many parous Bedouin women who utilise PNC is inadequate in complete protein and important micronutrients (namely $\mathrm{Ca}, \mathrm{Fe}, \mathrm{Zn}$, vitamin A and folate). Current public health recommendations for pregnant women in Israel, a high-income country, are suited for a population that has moved beyond the receding famine stage of the nutrition transition and is not at risk of an inadequate intake of multiple nutrients. These recommendations may thus not adequately address the needs of women who are experiencing overlapping nutrition transition stages, and the co-existing problems of inadequate nutrient intakes and an increasing risk of obesity. 


\section{Acknowledgements}

This research was supported by a grant from the Israel National Institute for Health Services and Health Policy Research (grant no. 03/136/A), and funds from the S. Daniel Abraham International Center for Health and Nutrition, Faculty of Health Sciences, Ben-Gurion University of the Negev, Israel. The authors would like to thank Douglas Midthune of the National Cancer Institute for his invaluable programming and analysis support. The contributions of the authors to the present study were as follows: K. A.-S. and D. F. designed and conducted the research; K. A.-S., D. R. S., L. S. F. and M. F. developed and carried out the data analysis plan; K. A.-S., H. V. and A. B. performed the statistical analyses; K. A.-S., D. R. S. and L. S. F. wrote the paper; and K. A.-S. had primary responsibility for the final content. All authors read and approved the final manuscript. The authors declare that there are no conflicts of interest in relation to this study.

\section{References}

1. Popkin BM (2006) Global nutrition dynamics: the world is shifting rapidly toward a diet linked with noncommunicable diseases. Am J Clin Nutr 84, 289-298.

2. Abu-Saad K \& Fraser D (2010) Maternal nutrition and birth outcomes. Epidemiol Rev 32, 5-25.

3. Madanat HN, Troutman KP \& Al-Madi B (2008) The nutrition transition in Jordan: the political, economic and food consumption contexts. Promot Educ 15, 6-10.

4. Delisle HF (2008) Poverty: the double burden of malnutrition in mothers and the intergenerational impact. Ann N Y Acad Sci 1136, 172-184.

5. Uauy R, Kain J \& Corvalan C (2011) How can the developmental origins of health and disease (DOHaD) hypothesis contribute to improving health in developing countries? Am J Clin Nutr 94, 1759S-1764S.

6. Allen LH (2005) Multiple micronutrients in pregnancy and lactation: an overview. Am J Clin Nutr 81, 1206S-1212S.

7. Christian P, Stewart CP, LeClerq SC, et al. (2009) Antenatal and postnatal iron supplementation and childhood mortality in rural Nepal: a prospective follow-up in a randomized, controlled community trial. Am J Epidemiol 170, 1127-1136.

8. Godfrey KM \& Barker DJP (2000) Fetal nutrition and adult disease. Am J Clin Nutr 71, 1344S-1352S.

9. Abu-Saad K, Shai I, Kaufman-Shriqui V, et al. (2009) Bread type intake is associated with lifestyle and diet quality transition among Bedouin Arab adults. Br J Nutr 102, 1513-1522.

10. Groen JJ, Balough M, Levy M, et al. (1964) Nutrition of the Bedouins in the Negev desert. Am J Clin Nutr 14, 37-46.

11. Central Bureau of Statistics (2006) Population 2006 - Table 3. Population of localities numbering above 1,000 residents and other rural populations on 31/12/2006. http://www.cbs.gov.il/ population/new_2007/table3.pdf (accessed September 2011).

12. Swirski S \& Hasson Y (2006) Invisible Citizens: Israel Government Policy Toward the Negev Bedouin. Beer-Sheva: HaMachpil Ltd.

13. Central Bureau of Statistics (2009) Local councils and municipalities - Rank, cluster membership, population, variable values, standardized values and ranking for the variables used in the computation of the index. http://www.cbs.gov. il/hodaot2009n/24_09_244t1.pdf (accessed September 2011).
14. Weitzman D, Shoham-Vardi I, Elbedour K, et al. (2000) Factors affecting the use of prenatal testing for fetal anomalities in a traditional society. Community Genet $\mathbf{3}$, $61-70$.

15. US Department of Agriculture (1995) Continuing Survey of Food Intakes by Individuals (CSFII) 1994. Washington, DC: CSFII.

16. Abu-Saad K, Shahar DR, Abu-Shareb H, et al. (2009) Assessing individual dietary intake from common-plate meals: a new tool for an enduring practice. Public Health Nutr 12, 2464-2472.

17. Thompson FE \& Subar AF (2008) Dietary assessment methodology. In Nutrition in the Prevention and Treatment of Disease, 2nd ed., pp. 3-40 [A Coulston and C Boushey, editors]. Burlington, MA: Academic Press.

18. Shai I, Vardi H, Shahar DR, et al. (2003) Adaptation of international nutrition databases and data-entry system tools to a specific population. Public Health Nutr 6, 401-406.

19. Abu-Saad K, Shahar DR, Vardi H, et al. (2010) Importance of ethnic foods as predictors of and contributors to nutrient intake levels in a minority population. Eur J Clin Nutr 64, S88-S94.

20. Food and Nutrition Board, Institute of Medicine (2005) Dietary Reference Intakes for Energy, Carbohydrate, Fiber, Fat, Fatty Acids, Cholesterol, Protein, and Amino Acids. Washington, DC: The National Academies Press.

21. US Department of Agriculture, Human Nutrition Information Service (1996) Food Intake Analysis System, version 3. Houston, TX: University of Texas Health Science Center at Houston School of Public Health.

22. Institute of Medicine, National Research Council (2009) Weight Gain During Pregnancy: Reexamining the Guidelines. Washington, DC: The National Academies Press.

23. Tooze JA, Midthune D, Dodd KW, et al. (2006) A new statistical method for estimating the usual intake of episodically consumed foods with application to their distribution. J Am Diet Assoc 106, 1575-1587.

24. National Cancer Institute (2011) Usual Dietary Intakes: SAS Macros for the NCI Method. http://riskfactor.cancer.gov/ diet/usualintakes/macros.html (accessed September 2011).

25. Murphy SP \& Poos MI (2002) Dietary reference intakes: summary of applications in dietary assessment. Public Health Nutr 5, 843-849.

26. Borum PR \& Broquist HP (1977) Lysine deficiency and carnitine in male and female rats. J Nutr 107, 1209-1215.

27. Hussain T, Abbas S, Khan MA, et al. (2004) Lysine fortification of wheat flour improves selected indices of the nutritional status of predominantly cereal-eating families in Pakistan. Food Nutr Bull 25, 114-122.

28. Belgnaoui S \& Belahsen R (2006) Nutrient intake and food consumption among pregnant women from an agricultural region of Morocco. Int J Food Sci Nutr 57, 19-27.

29. Cheng Y, Dibley MJ, Zhang X, et al. (2009) Assessment of dietary intake among pregnant women in a rural area of western China. BMC Public Health 9, 222.

30. Khoushabi F \& Saraswathi G (2010) Impact of nutritional status on birth weight of neonates in Zahedan City. Iran. Nutr Res Pract 4, 339-344.

31. Food and Nutrition Board, Institute of Medicine (2000) Dietary Reference Intakes for Vitamin A, Vitamin K, Arsenic, Boron, Chromium, Copper, Iodine, Iron, Manganese, Molybdenum, Nickel, Silicon, Vanadium, and Zinc. Washington, DC: National Academies Press.

32. Brune M, Rossander-Hulten L, Hallberg L, et al. (1992) Iron absorption from bread in humans: inhibiting effects of 
cereal fiber, phytate and inositol phosphates with different numbers of phosphate groups. J Nutr 122, 442-449.

33. Scholl TO (2005) Iron status during pregnancy: setting the stage for mother and infant. Am J Clin Nutr 81, 1218S-1222S.

34. Hartini TNS, Winkvist A, Lindholm L, et al. (2003) Nutrient intake and iron status of urban poor and rural poor without access to rice fields are affected by the emerging economic crisis: the case of pregnant Indonesian women. Eur I Clin Nutr 57, 654-666.

35. Khatib I \& Elmadfa I (2009) Poor nutritional health of Bedouin preschool children in Jordan: the irony of urbanization. Ann Nutr Metab 54, 301-309.

36. Kalter-Leibovici O, Atamna A, Lubin F, et al. (2007) Obesity among Arabs and Jews in Israel: a population-based study. Isr Med Assoc J 9, 525-530.
37. Mehio Sibai A, Nasreddine L, Mokdad AH, et al. (2010) Nutrition transition and cardiovascular disease risk factors in Middle East and North Africa countries: reviewing the evidence. Ann Nutr Metab 57, 193-203.

38. Satpathy HK, Fleming A, Frey D, et al. (2008) Maternal obesity and pregnancy. Postgrad Med 120, E01-E09.

39. Davis EM, Stange KC \& Horwitz RI (2012) Childbearing, stress and obesity disparities in women: a public health perspective. Matern Child Health J 16, 109-118.

40. Gottlieb N (2005) On the Path to Health: Access to Antenatal Care in the Unrecognized Villages of the Negev. Tel Aviv: Physicians for Human Rights-Israel.

41. Dodd KW, Guenther PM, Freedman LS, et al. (2006) Statistical methods for estimating usual intake of nutrients and foods: a review of the theory. J Am Diet Assoc 106, $1640-1650$. 